\title{
UNDER THE MICROSCOPE
}

Jose M. Carnate, Jr., MD

Department of Pathology

College of Medicine

University of the Philippines Manila

Correspondence: Dr. Jose M. Carnate, Jr. Department of Pathology

College of Medicine, University of the Philippines Manila

547 Pedro Gil St. Ermita, Manila, 1000

Philippines

Phone (632) 85264450

Telefax (632) 84003638

Email: jmcarnate@up.edu.ph

The author declared that this represents original material that is not being considered for publication or has not been published or accepted for publication elsewhere, in full or in part, in print or electronic media; that the manuscript has been read and approved by the author, that the requirements for authorship have been met by the author, and that the author believes that the manuscript represents honest work.

Disclosures: The author signed a disclosure that there are no financial or other (including personal) relationships, intellectual passion, political or religious beliefs, and institutional affiliations that might lead to a conflict of interest.

\section{Inverted Ductal Papilloma of the Salivary Gland}

This is a case consult of slides stated to be from an excision of a buccal mucosa mass in a 58-year-old-man. The specimen was described as a $3 \mathrm{~cm}$ diameter roughly oval tan-gray tissue with a $2 \times 1.5 \mathrm{~cm}$ mucosal ellipse on the surface that has a central ulcerated punctum. Cut section showed an underlying $1.7 \mathrm{~cm}$ diameter roughly oval well-circumscribed mass with a granular tan surface. Histological sections show a papillary lesion with an orifice on the mucosal surface and with epithelial nests invaginating into the underlying lamina propria in a non-infiltrative pattern. (Figure 1) The lesion is composed of papillary epithelial fronds with cleft-like spaces between the fronds. (Figure 2) The papillary fronds are lined by non-keratinizing basaloid stratified squamous cells with a superficial layer of columnar glandular cells along with mucous goblet cells interspersed among the squamous cells. (Figure 3) All the cellular components are devoid of cytologic atypia and mitoses. Based on these microscopic features we signed the case out as inverted ductal papilloma (IDP).

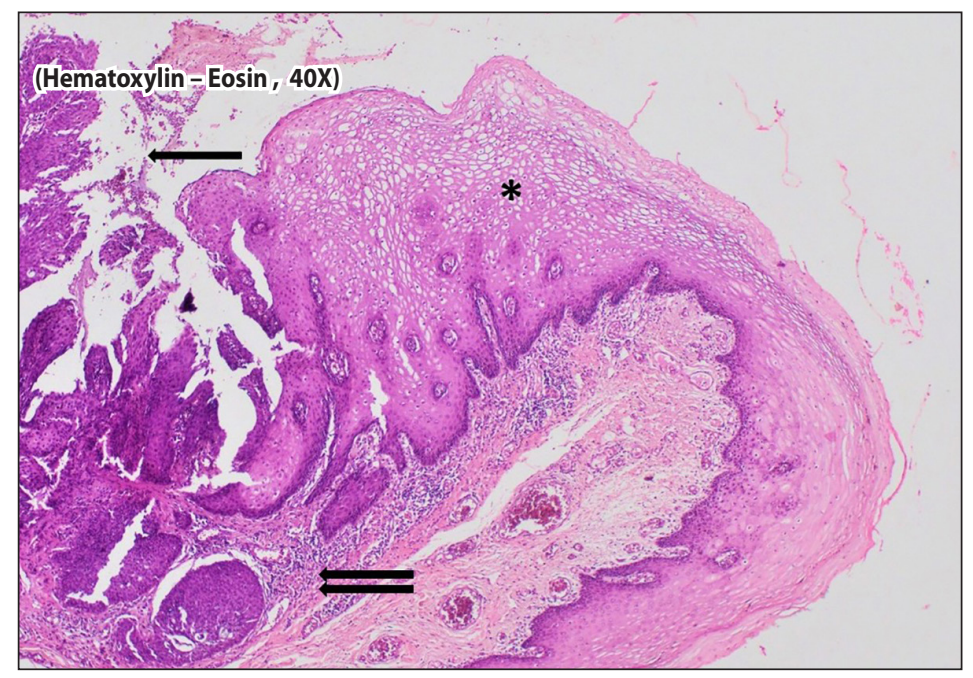

Figure 1. Papillary lesion with an orifice on the mucosal surface (single arrow) and with epithelial nests invaginating ("inverted") into the underlying lamina propria (double arrow). Note the adjacent squamous epithelium of the oral cavity mucosa (asterisk) (Hematoxylin-Eosin, 40X magnification). 


\section{UNDER THE MICROSCOPE}

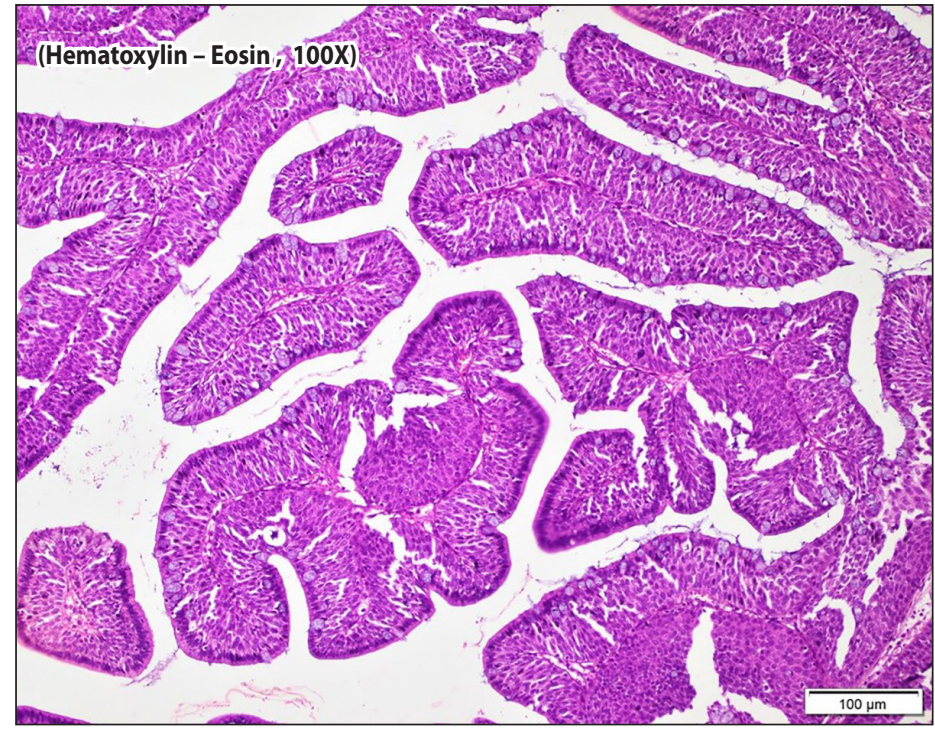

Figure 2. The lesion is composed of papillary epithelial fronds with cleft-like spaces between the fronds (Hematoxylin-Eosin, 100X magnification).

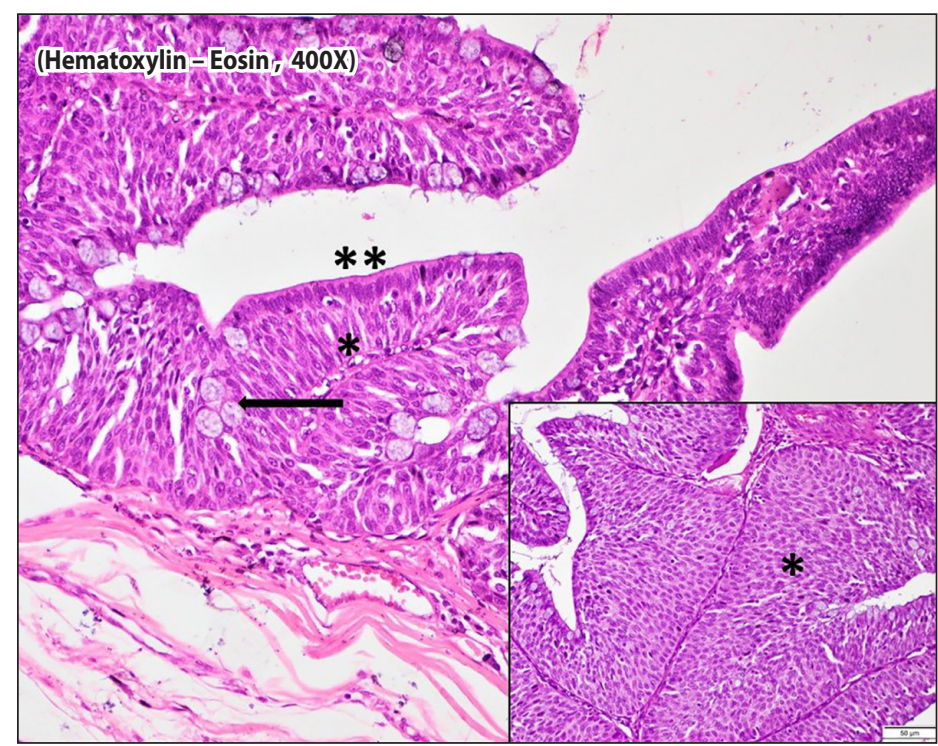

Figure 3. The papillary fronds are lined by non-keratinizing basaloid stratified squamous cells (single asterisks) with a superficial layer of cuboidal to columnar ductal-type glandular cells (double asterisk) note the presence of interspersed mucin-containing goblet cells (arrow) (Hematoxylin-Eosin, 400X magnification).

Ductal papillomas are uncommon benign epithelial tumors with a papillary configuration that originate from the excretory ductal system of salivary gland acini..$^{1-3}$ The World Health Organization recognizes two sub-types depending on the growth pattern: an intraductal papilloma (IP) and an IDP.' An IDP usually presents as an asymptomatic submucosal nodule, measuring about 1.5 centimeters in diameter, and most commonly involving the buccal mucosa, followed by the lips, palate, and floor of the mouth. ${ }^{2,3}$ Histological sections typically show an unencapsulated though well-circumscribed epithelial proliferation with a papillary configuration on the luminal surface, and a nodular, endophytic or invaginating ("inverted") configuration at its interface with the underlying lamina propria. ${ }^{2}$ Both the papillary and the invaginating areas are composed of basaloid, non-keratinizing stratified squamous epithelium that are often covered with a cuboidal or columnar ductal cell layer. ${ }^{2}$ Scattered among these are mucous goblet cells which can form microcysts. ${ }^{1,2}$ There is an overall morphological similarity to the sinonasal inverted papilloma. ${ }^{3} \mathrm{~A}$ relationship to trauma has been proposed. ${ }^{1,4}$ Association with Human Papilloma Virus (HPV) has also been reported.' Others, however, have not been able to demonstrate this association. ${ }^{4}$

Differential diagnoses primarily include IP - which is differentiated from IDP architecturally by being a unicystic intraluminal papillary proliferation within a dilated excretory duct ${ }^{2}$ - and sialadenoma papilliferum - which is predominantly polypoid and pedunculated with a verrucoid surface rather than a submucosal nodule, and an over-all morphologic similarity to the cutaneous tumor syringocystadenoma papilliferum. ${ }^{1,4}$ An important differential diagnosis that has to be ruled out is mucoepidermoid carcinoma (MECA) because of the presence of both squamous and mucin-secreting cells. MECA is distinguished by poor circumscription, and an infiltrative solid-cystic growth pattern. ${ }^{2,4}$

IDP is benign and non-recurrent. Unlike the nasal tumor, there has been no report of malignant transformation., ${ }^{2,3}$ Complete surgical excision is considered curative., ${ }^{1,2}$ Reporting these cases is encouraged to further our knowledge of the entity and elucidate a potential association with HPV.

\section{ACKNOWLEDGEMENTS}

The author wishes to acknowledge Dr. Erodulf L. Petilla and Dr. Maximo A. Saavedra for the case referral.

\section{REFERENCES}

1. Richardson M, Bell D, Foschini MP, Gnepp DR, Katabi N. Ductal papillomas. In: El-Naggar AK, Chan JKC, Grandis JR, Takata T, Slootweg PJ. World Health Organization Classification of Head and Neck Tumors. IARC: Lyon 2017; p. 192-193.

2. Gnepp DR, Henley JD, Simpson RHW, Eveson J. Chapter 6: Salivary and Lacrimal Glands. In: Gnepp DR. (editor) Diagnostic Surgical Pathology of the Head and Neck. 2nd edition. Philadelphia: Saunders Elsevier. 2009; p. 469-471.

3. Berridge N, Kumar M. An interesting case of oral inverted ductal papilloma. Dent Update 2016 Dec;43(10):950-2. DOI: 10.12968/denu.2016.43.10.950. PubMed PMID: 29155535.

4. Sala-Perez S, Espana-Tost A, Vidal-Bel A, Gay-Escoda C. Inverted ductal papilloma of the oral cavity secondary to lower lip trauma. A case report and literature review. J Clin Exp Dent 2013 Apr 1;5(2):e112-6. DOI 10.4317/jced.51055 PubMed PMID: 24455058 PubMed Central PMCID: PMC3892218. 